\title{
The Effect of The International Code of Conduct on Pesticide Management on the Use of Pesticide in Kerala, India (2003-2017)
}

\author{
Mutia Hariati Hussin ${ }^{1, *}$ Esti Kukuh Perbawati ${ }^{2}$ \\ ${ }^{1}$ International Relations Department, Universitas Muhammadiyah Yogyakarta \\ ${ }^{2}$ Master of Environmental Science, Gadjah Mada University \\ *Email: mutiahussin.suryo@umy.ac.id
}

\begin{abstract}
The use of pesticides initially was governed by the Code of Conduct on the Distribution and Use of Pesticide. The State of Kerala in India had been using pesticides to eliminate malaria, and in 1962, the Plantation Cooperation of Kerala began spraying pesticides by plane regularly three times every year. After that, the problems caused by pesticides were increasingly widespread due to uncontrollable usage and distribution in Kerala. Until around the 2000s, there were many problems caused by it, and the impact of uncontrolled pesticide use both directly and indirectly affected humans and the environment. Therefore, the Government of Kerala began drafting local regulations regarding pesticides based on the new Governance of The International Code of Conduct on Pesticide Management. The local regulators set up the necessary measure to accommodate the new regulation on pesticide management that became effective in Kerala, India.
\end{abstract}

Keywords: pesticide management, Kerala, Code of Conduct, intervention, local regulation

\section{RESEARCH BACKGROUND}

Kerala is a state in India, precisely located in the southwestern part. Its location is directly adjacent to Tamil Nadu, where Thiruvananthapuram is its capital. Geographically, Kerala is close to the Indian Ocean to the west and south. Administratively, Kerala consists of 14 districts, which are Thiruvananthapuram, Kollam, Alappuzha, Pathanamthitta, Kottayam, Idukki, Ernakulam, Thrissur, Palakkad, Malappuram, Kozhikode, Wayanadu, Kannur, and Kasaragod [1]. Kerala has very fertile land, abundant water, and quite a variety of flora and fauna. The existing valleys and forests are home to rural Kerala people. With natural resources provided by Kerala, the majority of the population's jobs in Kerala are farming. Due to Kerala's abundant natural wealth, many companies took this to gain advantages, unfortunately with Kerala government assistance. For example, the Kerala Plantation Company, the largest plantation company in the public sector, was founded by the Kerala Government in 1962. The purpose of establishing the company was due to develop the Agra-economy aspect of Kerala. This area is 14,020 hectares, mostly with rubber trees and oil palm planting, while the rest was with cinnamon, coconut, pepper, teak trees, and cashews [2]. The World Health Organization (WHO) stated that there had been around 400,000 to 2 million pesticide poisoning cases, which caused 10,000-40,000 people dying every year from all over the world. In 2009 WHO estimated that at least 300,000 people died each year from pesticide poisoning [3].

\subsection{History of Pesticide Use}

Pesticides are a type of chemical product used to kill plant pests. Pesticides have long been uses by humans. A study found that the first recorded use of insecticides was approximately around 4,500 years ago by the Sumerians that used a sulfur compound to expel insects and mites. About 3200 years ago, the Chinese people used mercury and arsenic compounds from the dried flower of Chrysanthemum cineraria folium "Aster pyrethrum," then used as an insecticide [4].

For several years, especially after World War II, chemical pesticides have become the most important and popular form of pest control. During World War II, 
DDT (Dhiclorodiphenyltrichloroethane) [5] was considered the most potent aid in saving soldiers from pest attacks, which were then used in the agricultural sector [6]. Agricultural products are imperative for the provision of food in almost every country. Even today, with advances in agricultural science, losses from pests and diseases range from 10-90\%, with an average of 35 to $40 \%$, for all potential food crops and fibers [4].

This pesticide innovation caused various problems, which in 1958 was written by Rachel Carson in her book entitled The Silent Spring as an eternal poison to the earth. What Carson described is similar to what happened in Kerala. Several districts in Kerala became empty due to pesticide use. Plants were wilted, animals and even small insects were destroyed. There was no more chirping sound of wild birds in Kerala at that time. Even children in Kerala were born with deformed limbs and became disabled due to pesticide use.

\subsubsection{Pesticide Use in Kerala}

In Kerala alone, at least 4,270 people were contaminated with pesticides, and 500 died by 2012 . The data were submitted by Kerala health officials [7]. With data availability on the number of victims due to pesticide poisoning, the international community and groups of NGOs (Non-Governmental Organizations) agreed to make an international regulation that would significantly control pesticides and curb the effects of pesticides on the environment and human sustainability. The WHO (World Health Organization) and FAO (Food and Agriculture Organization) had the Code of Conduct on the Distribution and Use of Pesticide in dealing with this problem. Later, after some adjustments, that Code of Conduct will be known as The International Code of Conduct on Pesticide Management [8].

According to the Economic Review, data recorded on the use of pesticides in Kerala from 1996-2008 is around 462.05 metric-ton. However, contamination decreased from $18 \%$ in 2013 to $8 \%$ in 2016 [9]. The contamination reduces recorded after the Kerala government began to follow the procedures in The International Code of Conduct on Pesticide Management [10]. Using the data related to the reduced use of pesticides in Kerala, researchers researched The International Code of Conduct on Pesticide Management in dealing with pesticide use in Kerala, India.

\section{METHOD}

This research used descriptive or qualitative methods. This method describes Kerala's phenomena to explain and determine the influence of The International Code of Conduct on Pesticide Management in dealing with pesticide use and its distribution in Kerala using data collection techniques, namely library research. Respectively, by collecting related data from searching for some literature related to the problem to be studied. The literature is in books, journals, documents, magazines, official reports, newspapers, articles, and other internet sources.

\section{LITERATURE REVIEW}

\subsection{Pesticide Use in The Rice Bowl of Kerala: Health, Cost, and Policy Option by Indira Devi}

Indira Devi (2017) stated that the high level of contamination, especially in India's fruits and vegetables, was caused by pesticides not adequately regulated or controlled, especially the BHC and DDT, mainly because their persistence in nature is damaging to the environment. Later, the level of pesticide consumption in India, as well as in Kerala, has decreased [11]. At that time, quality control and control of pesticide use have been regulated by the pesticide inspector or agricultural officers appointed by the Kerala government Department of Agriculture. Indira Devi further explained that even though quality control has existed, they are still below standard, and there has been no further action to assure its effectiveness [11].

The research conducted by Indira Devi concluded that the use of pesticides, which were less scientific and still not adequately regulated, leads to an increase in the number of victims due to pesticide contamination, especially in Kerala. This contamination causes a disease that is riskier and has a long-term effect on nature. According to Indira Devi (2007), the increasing number of victims with chronic diseases could also increase state funding on health and treatment, when some states do not think about this long-term impact. Of course, this large expenditure could be more effectively controlled by looking for safer alternatives in using pesticides and employ support from various parties, especially the government, to protect human health, the environment, and agricultural products.

\subsection{Pesticide in Agriculture; A Boon or Curse? Case Study of Kerala by Indira Devi}

India is a well-known producer of pesticides in Asia. The nation ranked 12 globally. Since 1948 the use of pesticides in India for the first time has been used BHC and DDT. The most widely used pesticides in India are herbicides and fungicides, especially for vegetable and fruit farming. The use of pesticides has also continued to increase, especially after the green revolution in India. 
The use of pesticides on agricultural land in Kerala itself still uses a conventional system of spraying. The observations and research conducted by Indira Devi (2010) show that pesticide spraying in Kerala on plants is prolactin and considered the most crucial thing to apply. However, farmers still use several hazardous chemicals until 2010 even though the government has already forbidden the practice, so the Kerala government removed several hazardous pesticides from the market.

Indira Devi (2010) also observed farmers' behavior in using pesticides on agricultural land. Most of the farmers observed did not follow the procedures recommended by the government. Where personal protection should be worn, there are faces, bodies, and shoes that comply with standards. $71 \%$ of respondents stated that they used some personal protective equipment, of which $21 \%$ wore long sleeves, although most would have rolled their clothes when applying pesticides and spraying. Also, $48 \%$ use the cloth to cover the nose, and only $1 \%$ wear glasses, although all the equipment needed has been provided [9].

The use of pesticides that are not following these procedures can lead to various health impacts on humans and environmental damage. In her research, Indira Devi stated that the lack of understanding regarding hazardous materials is also a problem in using pesticides in Kerala. The community, especially farmers, still found it challenging to understand the color differences in the categorization of chemicals in pesticides, where $99.5 \%$ of observed farmers did not understand the toxicity through the color marks on the packaging [9].

Indira Devi mentions that the highest rate of pesticide poisoning in Kerala is suicide using pesticides, about $60 \%$ of $100 \%$ of the number of cases of suicide using pesticides. Besides, pesticide contamination victims also occurred accidentally, such as from pesticide spills due to the storage of pesticides that are not following procedures. Pesticide contamination can also occur when making direct contact with pesticides, especially in the agricultural sector, when spraying and after spraying. Indira Devi (2010) also mentions various direct impacts of excessive use of pesticides that are not following standards.

Technological advances in ecology have paved the way for healthier and more sustainable agriculture. In her research, Indira Devi (2010) found that although the use of pesticides has tended to decline, unfortunately, the regulation of the use of chemicals that are very dangerous and prohibited was limited to prevent unwanted things.
Some farmers would buy pesticides that other farmers think are more effective but composed of more harmful content or get it directly from producers who approach them to offer their products without government control. It also affects the handling pattern of pesticide use, proven to be unscientific and using poorly regulated management.

Based on the things mentioned above, Indira Devi (2010) concluded that policy intervention is needed to regulate pesticides more effectively. Through counseling on the use of chemicals that are safer and more sustainable. Besides, management control also needs to be improved and monitored to be more sustainable. The existing system already in place, but its implementation has not been implemented effectively. Public and farmer awareness about the existing law and system can also be done by conducting simple but supervised extension services. Ecologically safe agricultural management systems can only be achieved by combining adequate legal support, effective monitoring, and concrete action by stakeholders [9].

\section{THEORY}

\subsection{International Environmental Regime Concept}

An international regime is defined as a group of authoritative ideas, conventions, rules, or epistemic practices that regulate a series of activities in specific issue areas in international affairs. These fields include trade, monetary exchange, agricultural policy, diplomatic privileges, nuclear proliferation, use of the sea, environmental regulation, and many others [12]. As for the definition put forward by Stephen Krasner, namely, "as a collection of principles, norms, rules, and implicit or explicit decision-making procedures around the actors' expectations that meet in an area of international relations [12]. The Principles are defined as a belief, in fact, reason, and honesty. Norms are standards of behavior that can be interpreted in terms of rights and obligations. Meanwhile, a rule is a special recipe or prohibition against an action. Decision-making procedures are practices that apply to making and implementing joint choices [13].

The concept of an international environmental regime is a regime articulated in international treaties, especially in environmental issues. The environmental regime itself is defined as a social institution consisting of agreed rules, roles, and norms [14]. According to Robin William, social norms itself, namely rules of conduct, determine what to do and what not to do by various actors, especially in various situations [15]. Based on behavior in making decisions, procedures and formulating and implementing regulations, there are two forms of norms. Substantive Norms provide specific standards regarding behavior rules [16], and Procedural 
Norms; guides how a country should design and use decision-making mechanisms [17].

A country sometimes has to share a little of its sovereignty to join the international environmental regime [18]. In its social sphere, the international environmental regime has the primary function of binding collective decision-making [19], thus allowing its members to adopt norms mutually agreed upon. All actors, not only the state, play a vital role in carrying out these norms.

From the regime concept point of view, The International Code of Conduct on Pesticide Management serves two functions. One is a binding agreement to implement standards regulated by the FAO and WHO, and two as guidelines to carry out the statutory planning issued by the FAO and WHO. Peter Hoge conveyed several norms related to the use of pesticides internationally, that is:

1. We must try to get optimal food yields (food security).

2. Disease and pest damage must be limited.

3. Misuse of pesticides that cause poisoning in humans must be prevented.

4. The pesticide trade must be regulated.

5. Pesticides should not be used excessively.

6. An environmental policy on pesticides must be made.

7. Food contamination due to pesticides should be limited [15].

\subsection{Compliance Bargaining Theory}

William Zartman initiated this theory. This idea led to a bargaining process in an agreement. The bargaining process in signing the agreement is closely related to the obligations that must be fulfilled in the agreement. This theory even underlines the importance of adherence to agreements and agreements that have been signed. This compliance is closely related to actors and good management in a regime. The compliance level is then seen from two sides: the School of Management and the School of Enforcement [20].

According to the Enforcement School, noncompliance arises because of various motives, in which this non-compliance must be dealt with effectively. According to Stein, all the various motives sometimes face a dilemma. Every country has the same interests, and it will be beneficial if it is complying with one another. However, sometimes there is a violation of commitment because one feels that it will provide other benefits. The violation, of course, is inversely proportional to what Management School believes. Management School emphasizes the clarity of an agreement. According to the Management School, if compliance is a problem, then the actual underlying problem lies with the management. If a policy is ambiguous and unclear or collides with the existing social-economy, there will be non-compliant. In the end, it has an impact on the ineffectiveness of the policy or regime [20].
Based on the explanation above, it can be concluded that in seeing a policy's ineffectiveness, the Compliance Bargaining theory refers to several causes. First, the level of compliance can be seen from the applicable policies. Does the current policy have a small and low capacity to increase compliance, or it could be caused by a lack of compliance by actors to fulfill and understand the existing policy? Second, in Compliance Bargaining, it is stated that the existing policies are still ambiguous or unclear, such as the language used in the policies is unclear and imprecise. This theory can see whether a policy or regime has explicit content, starting from the ideas to the language used and the regime's aims and objectives [21].

If the Compliance Bargaining theory is applied in the regime discussed, that is to say, The International Code of Conduct on Pesticide Management. Thus, various implemented regulations will be efficient and useful if they have clear ideas and language, and clarity of regulations to control and supervise all activities related to the use and distribution of pesticides.

\section{DISCUSSION}

Pesticides Poisoning is a clinical diagnosis that includes critical-poisoning and sub-critical poisoning or diseases (dermatological, systemic to Ophthalmological) caused by exposure to pesticides [22]. The WHO refers to Acute Pesticide Poisoning, namely all diseases or health effects resulting from confirmed or suspected pesticide exposure within 48 hours [23]. One of the great tragedies that caught the world's attention in the early 2000s was Kerala, the Indian state.

Pesticide use in Kerala has a very long history. Almost all districts in Kerala use pesticides on their agricultural land. Kerala has focused on various studies and observers of pesticide use since 1958 when 100 people are declared dead due to pesticide poisoning after consuming wheat flour, which has been contaminated. In 1978, there was an immense tragedy in Kerala, in the Kasaragod district. When pesticides are sprayed by airplanes, it can also kill the environment. Since the beginning, the spraying carried out by the Kerala Plantation Company has received many warnings from nature. This warning comes from the many deaths of small insects, fish in the river, frogs, foxes, and even livestock belonging to locals [24]. It was followed by the number of residents who experienced health problems - starting from cancer to mental disorders. Another tragedy occurred in the Kuttanad district, Kerala [25], where rice contained pesticides found. Pesticide residues on vegetables in India are the largest in the world caused by the unregulated use of pesticides [11].

The use of pesticides by farmers in Kerala is not matched by correct use procedures, coupled with 
inadequate government control over trade and pesticide distribution. Careless use, spraying barefoot and not wearing gloves, using airplanes, illegal sale of pesticide, and careless disposal of pesticide containers are not well supervised by the government. They become significant problems, not only in Kerala but almost in all states in India. Kerala's condition, which was seriously affected by pesticides, was finally brought to international conventions and led the Kerala government to phase out several pesticides in 2001 finally. Kerala's government is not alone, and many international organizations have also helped in renewing Kerala from pesticide disaster. Among other things are amendments to several laws and government regulations related to pesticides' use and distribution.

One of the international regulations used in various conventions, especially those related to pesticides, is The International Code of Conduct on the Use and Distribution of Pesticide, referred to as Governance. The Governance was created after the second FAO Government Consultation in the International Harmonization of Pesticides Registration Requirement in Rome, 1982, which resulted from pressure from WHO and other NGOs on the issue of Pesticide Poisoning. This Governance is divided into two main concentrations, namely Pesticide Poisoning and international pesticide sales [15]. These two essential points aim to minimize Pesticide Poisoning victims' number in humans and the environment [26].

\subsection{International Governance Reform of Pesticide Management 2002-2013}

This Governance has undergone many revisions since 1989, 2002, 2009, to 2013. Formerly known as the Code of Conduct on the Use and Distribution of Pesticide, its renewal form as The International Code of Conduct on Pesticide Management promises better arrangement on the use and distribution of pesticides. According to the Director-General of FAO, this renewal is the answer to the many pesticide management problems. The renewal process has run since 1999, which is the input or recommendation from FAO, NGOs, Government Expert Institutions, the pesticide industry to other UN organizations [26]. In the latest revision, this Governance emphasizes a fair management process from production to disposal, which involves and carried out everyone's responsibility to protect the community's health and the surrounding environment. Governance is paying greater attention to several aspects such as health, the environment, and crop protection products. Updating some definitions and requirements and aligning guidance in several technical areas with international chemical management developments was also carried out until its name was officially changed to The International Code of Conduct on Pesticide Management [27].

FAO recommends that all FAO member countries promote this Governance for the sake of safer and more efficient use of pesticides in the year when the regulation was first applied until nowadays. The standardized Governance for Use and Distribution of pesticides and the guidelines for their implementation provides the most comprehensive international standards for addressing the problem caused by pesticides. Although voluntary, this Governance has significant support from various elements, such as government, private sector, and public interest groups, including PAN (Pesticides Action Network) and other non-governmental organizations [28]. Since its application in 1985, Governance is highly accepted and serves as a global standard, especially in protecting the environment and human health. This Governance also explains about HDI (Integrated Pest Management) and IVM (Integrated Vector Management) as an alternative to pesticides and as an effort to protect public health.

The FAO Director-General Jose Graziano da Silva once commented on The International Code of Conduct on Pesticide Management. "This new Governance provides a framework that guides government regulators, the private sector, civil society and other stakeholders on best practices in managing pesticides throughout its life cycle" [29].

The same thing was conveyed by Margaret Chan, Director-General of WHO, 'Governance is designed to be used in each country's national laws.' Governance clearly illustrates the shared responsibility of various sectors. That is to say, to answer the need for a cooperation framework, the need to strengthen the capacity to implement these regulations and describes appropriate standards for the management of pesticides as a complement to legally binding instruments on the management of chemicals (especially those that are highly hazardous This regulation serves as a framework or guide to strengthen member states' capacity, especially developing countries, to regulate, evaluate, and enforce sufficiently adequate controls over pesticides, including those used for public health, those traded, and those used on individual countries territory [29].

Improvements in 2002-2009 were made concerning the establishment of PIC (Prior Informed Consent) as a mandatory standard in the Rotterdam Convention. The reforms made in 2002 were an answer to doubts about the safe use of pesticides, especially in developing countries, so that the Governorship was updated and began to discuss the importance of reducing and 
eliminating the dangers of pesticides. PAN acknowledged these weaknesses, that is to say:

"There are still major weaknesses in certain aspects of pesticide management, predominantly in developing countries. For instance, national pesticide legislation is not widely enforced due to a lack of technical expertise and resources. Highly hazardous or sub-standard pesticide formulations are still widely sold, and end-users are often insufficiently trained and protected to ensure that pesticides can be handled with minimum risk" [28].

Those weaknesses are mainly found in several aspects of pesticide management, especially in developing countries where the regulations on pesticides are not widely applied and the lack of technical resources experts in handling it. Of course, this must be given more concern so that pesticide use management can run adequately and efficiently. Then followed by 2004, the Rotterdam Convention on PIC and the Stockholm Convention on POPs, so that the Governance was re-updated and included the two elements. In the Rotterdam Convention, it is stated that hazardous substances or pesticides that have been sold may not be exported or imported, except for obvious reasons, and do not cause adverse effects. Meanwhile, the Stockholm Convention [31] eliminates the production and use of pesticides included in POPs [28]. related to pesticide contamination globally, especially in developing countries.

Until 2008, FAO and WHO conducted the FAO/WHO Joint Meeting on Pesticide Management, and added HHP (Highly Hazardous Pesticides) as an important part of reducing pesticide use. In 2013, The Code of Conduct on The Distribution and Use of Pesticide had changed its name to become The International Code of Conduct on Pesticide Management. This change responds to the victim due pesticides in developing countries, coupled with the sale of dangerous pesticides that are still occurring [28]. In addition, in early 2001, the international community was shocked by the data related to the number of victims and environmental damage in Kerala, India, due to the use of pesticides followed by the many cases of other pesticide poisonings from various countries.

FAO and WHO will make improvements after the existence of the JMPM (Joint Meeting on Pesticide Management), where all members will provide input and review regarding how often a guideline issued is used or not. Where guidelines are most widely used, reflect most countries' needs today, especially countries in Asia, where pesticides are mostly used. Later this design will update the Governance in Pesticide Management so that it is related to the need to run effectively [30]. The reforms that are no less important

Table 1. The Revision of The International Code of Conduct on Pesticide Management

\begin{tabular}{|c|c|c|}
\hline & Before the Revision & After the Revision \\
\hline Idea & $\begin{array}{l}\text { It is only limited to the framework for each } \\
\text { country in which the FAO, Government, and the } \\
\text { pesticide industry is mentioned. }\end{array}$ & $\begin{array}{l}\text { Strengthening capacity through } \\
\text { cooperation between entities and FAO } \\
\text { member countries, with the addition of } \\
\text { producers, sellers, users, and all NGOs } \\
\text { dealing with the environment and } \\
\text { pesticides }\end{array}$ \\
\hline Aim & $\begin{array}{l}\text { Oversee sales to minimize casualties and } \\
\text { environmental damage }\end{array}$ & $\begin{array}{l}\text { To maximize the benefits of pesticides in } \\
\text { order to effectively control pest, while } \\
\text { maintaining human health and the } \\
\text { environment and supporting research to } \\
\text { replace chemical pesticides }\end{array}$ \\
\hline Language & $\begin{array}{l}\text { 1. Only accessible in English } \\
\text { 2. Using code in technical guides as well as } \\
\text { terms that are difficult to understand }\end{array}$ & $\begin{array}{l}\text { 1. Available in English, Chinese, Russian, } \\
\text { Arabic, French and Spanish } \\
\text { 2. No longer using codes and term } \\
\text { 3. Improved definition }\end{array}$ \\
\hline
\end{tabular}

In the following years, international organizations, such as FAO and WHO, in collaboration with other organizations, conducted research and data collection are the ideas, objectives, and language in Governance related to Pesticide Management, which can be seen in more details on table 1.: 


\subsection{The Condition in Kerala After the Governance Reform}

Kerala has a quite severe level of damage because it has been using pesticides uncontrollably for almost 30 years. According to the Kerala Ministry of Agriculture, pesticide contamination decreased from 2013 to 2017 [10]. After the Governance related to pesticide management was renewed in 2013, the Kerala government has increasingly tightened its control over pesticides. The Kerala government controls pesticide residues and contamination through research conducted by organizations and the Kerala Agricultural University. Many pesticide inspectors are proven to control the sale and use of pesticides in Kerala, especially in border areas, where illegal pesticides are often traded.

Figure 1. Number of Pesticide Inspectors in India is based on laboratory results conducted at the Faculty of Agriculture in Vellayani, from May to April 2016. According to Thomas Biju Mathew, Professor, and Head of the KUA Laboratory, confirming these results, he even said that this is one of the results of public awareness of the dangers of pesticides that have been campaigned by the government and environmental organizations. In addition, the Kasaragod district, one of the areas previously hardest hit by pesticides, is now the only district in the state that is highly organic [32]. The claim is also supported by the results of a study conducted by Indira Devi (2010) that the consumption of hazardous materials in agriculture has decreased, even though safe materials are still in tiny amounts [9].

In 2017, based on a report collected by the Kerala Agriculture University, around $93.6 \%$ of Kerala's vegetables were free from pesticide contaminations.

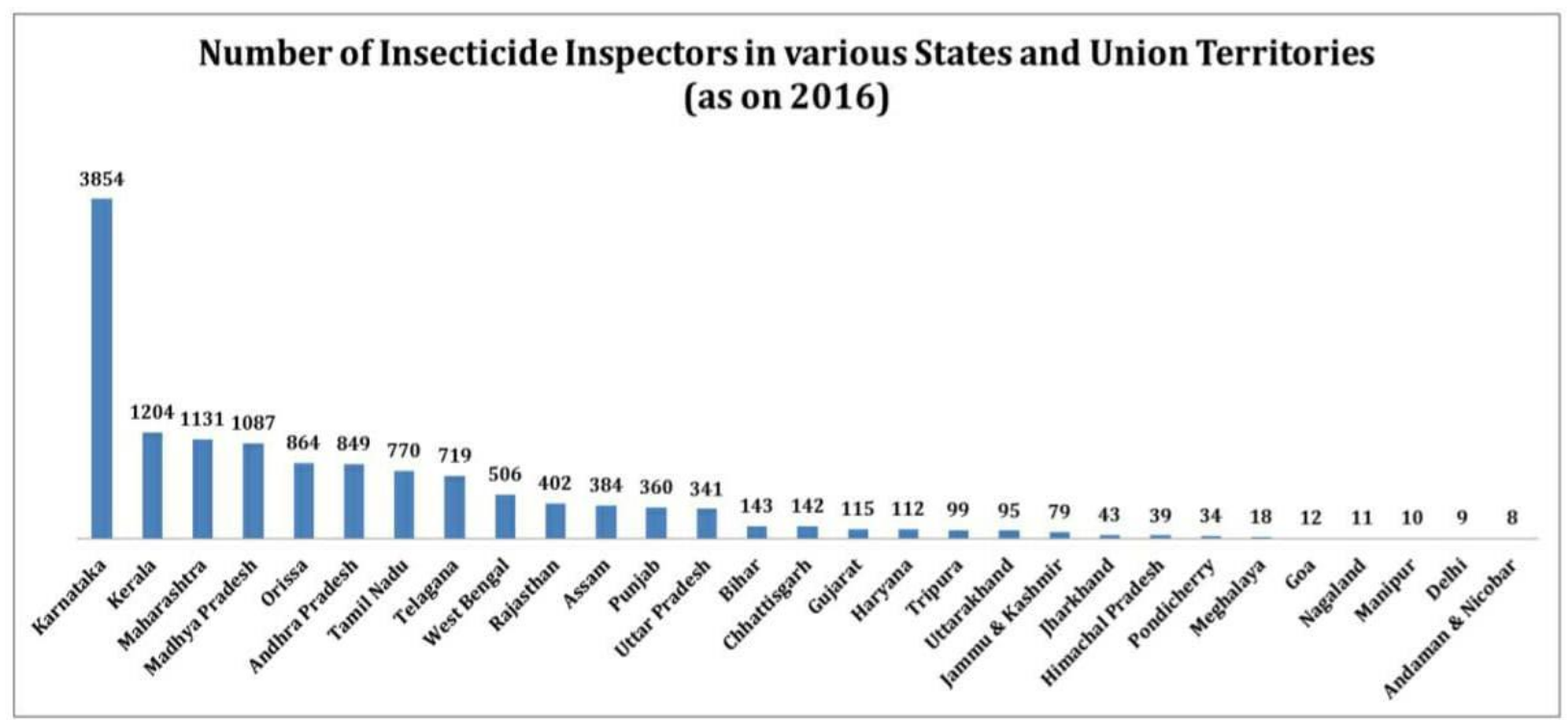

The Kerala government sent these inspectors to each district, especially the districts which directly border Tamil Nadu. Kerala itself has the second largest number of inspectors in India, 1,204 inspectors [31]. The inspector is part of the enforcer who controls the use, sale, and disposal of containers and pesticide waste. They also have an obligation to submit monitoring and evaluation results to the Kerala government, which will then be forwarded to India's central government. Many insecticide inspectors in Kerala do not mean that the Kerala government will stop promotion and education related to pesticides. With these insecticide inspectors' presence, the government has intensified campaigns, especially related to organic farming. It continues to increase security, especially in districts that are directly adjacent to other states in India.

According to a report released by the Kerala Agriculture University (KAU), pesticide residues on vegetables in Kerala have fallen drastically. The report
Samples were collected from three districts: Kottayam, Kannur, and Wayanad, declared free of pesticides [33]. The data collected is evidence of the Kerala government's efforts in evaluating the use and distribution of pesticides. The Kerala government also collaborates with various environmental organizations, shown on the data presented, especially those focusing on handling pesticides in promoting matters related to pesticides.

Responding to the latest Governance updates related to pesticide management, the Kerala government has also further strengthened its cooperation with various environmental organizations at home and abroad. In 2017, the Kerala government, through its Minister of Agriculture, Sunil Kumar, said that in order to minimize the use of the latest generation of pesticides and the entry of pesticides from other countries, the government would open four high-tech laboratories in Kerala [34]. 
In the early 2000s, Kerala had plenty of data related to the number of victims due to the high pesticide contamination and a very worrying picture of environmental damage. So now Kerala can minimize this by reducing the use of pesticides, active promotions and campaigns related to organic farming and the dangers of pesticide use, coupled with the education given to all farmers, as well as strict supervision of the border areas made the number of victims no longer high.

Until 2017, the government continues to provide compensation to victims due to pesticides and take a firm stance on agricultural products that enter Kerala from other countries if there are pesticide residues. This government policy is a step towards $100 \%$ organic farming by 2020. In addition, Kerala's people also receive education regarding the purchase, use, and disposal of pesticide containers.

\section{CONCLUSION}

Advances in environmental science and technology have led to better public attitudes and concerns regarding the use of pesticides. Through research conducted by Kerala Agricultural University, environmental damage and the many reports of victims due to pesticides have attracted public attention. As a result, the government pays more attention to these problems. Changes made by FAO and WHO in Governance related to Pesticide Management are also the result of the evaluation and monitoring of all activities that use pesticides and the number of victims caused by pesticides, including what happened in Kerala. The changes in Governance also prompted the Kerala government to be more serious in taking action, especially since India is an FAO member. The Kerala government is also carrying out increasing activities such as research on pesticide substitutes, monitoring of use, as well as campaigns and education related to pesticides to reduce the number of poisoning caused by pesticides.

Based on the above discussion, it can be concluded that the implementation of Governance related to Pesticide Management that is carried out by the Kerala government using new ideas, objectives, and local language through campaigns, supervision, and education about pesticides for the community. In this regard, the government's seriousness then showed significant results until 2017, namely a decrease in the use of hazardous chemicals on agricultural land and in the level of contamination in agricultural products.

\section{AUTHORS' CONTRIBUTIONS}

An international regime will work more effectively when the implementation process involves user-friendly
Governance and guidelines supported by local regulators and enforcers. In this case, the Code of Conduct on Pesticide Management, after it is amended, succeeds in promoting the proper use of pesticides to reduce its harmful effects. It conveys the idea of involving various elements of society, including government, organizations to academics, business people, and local regulators' interests through the use of functioning regulations consisting of familiar language and expressions.

\section{ACKNOWLEDGMENTS}

This publication is part of the Student-lecturer collaborative research target output. Our sincere gratitude to Universitas Muhammadiyah Yogyakarta (UMY) for the opportunity to present the paper in the International Symposium on Social Sciences, Humanities, Education, and Religious Studies (ISSHERS) at the International Conference on Sustainable Innovation 2020 (ICoSI 2020) hosted by UMY in October 2020.

\section{REFERENCES}

[1] Kerala District. Retrieved Mei 25, 2018, from The Official Web Portal: https://kerala.gov.in/districts

[2] Beyond Pesticide. Endosulfan Found in Bone Marrow of Children with Blood Cancer, 2012. DOI: http://beyondpesticides.org

[3] Tussolihin, K. D. Quantitative Analysis of Profenofos Insecticide Residues on Fresh Red Chili and Milled Red Chili in Several Traditional Markets in Medan City, 2012, Repository USUDOI: http://repository.usu.ac.id

[4] Unsworth, J. History of Pesticide Use. IUPAC, 2010. DOI: http://agrochemicals.iupac.org

[5] The Center for Disease Control and Prevention. DDT, 2009. DOI: http://npic.orst.edu

[6] Fishel, F. M. Pest Management and Pesticides: A Historical Perspective. IFAS Extension, University of Florida, 1-5.

[7] The Ecologist. The Child Victims of Pesticides Poisoning in India. 2012. DOI: http://theecologist.org

[8] CropLife International. The International Code of Conduct, 2019. DOI: https://croplife.org

[9] Four Years of Pesticide Surveillance Pays Off, Times of India, 2017. DOI: http://timesof india.indiatimes.com

[10] Devi. I. Pesticide in Agriculture: A Boon or Curse? Case Study of Kerala. Review of Agriculture, 2010, pp. 199-207. 
[11] Devi. I. Pesticide Use in the Rice Bowl of Kerala: Health Costs and Policy Option. SANDEE Working Paper, No. 20-07, 2007, pp. 1-40.

[12] Hopkins, R \& Meiches, B. Regime Theory. Oxford Research Encyclopedia International Studies, 2018. DOI: http://internationalstudies.oxfordre.com

[13] Mushkat, R. Compliance With International Environmental Regimes: Chines Lessons. William and Mary Environmental Law and Policy Review Vol. 34, Issue, 2, 2010, pp. 493-573.

[14] Harris, F. Global Environmental Issues. England: Willey Blackwell, 2012.

[15] Houge, P. The Global Politics of Pesticides Forgoing Consensus from Conflicting Interest. UK: Earthscan Publication, 1998, p. 10.

[16] International Regimes. Repository UNIKOM. DOI: https://repository.unikom.ac.id

[17] Arian, Y. Chapter 1. Eprints UMM, p. 13. DOI: http://eprints.umm.ac.id

[18] Lopes, P. D. International Environmental Regimes. IIASA Working Paper, 3, p. 2.

[19] Gehring, T. International Environmental Regimes as Decision Machines. Otto Friedrich Universitat Bombergh, 2012.

[20] Jonsson, C \& Tallberg, J. Compliance and PostAgreement Bargaining. ResearchGate: European Journal of International Relations, 1998, p. 374.

[21] Pratiwi, T. D. The Effectiveness of Indonesian Policies in Addressing Shark Hunting Issues. Thesis of Muhammadiyah University of Yogyakarta, 2017, pp. 21-22.

[22] Oregon Health Authority. Pesticide Poisoning. Public Health Division, Environmental Public Health, 2019, p. 2. DOI: https://www.oregon.gov

[23] Thundiyi, J. G., Stober, J., Besball, N., \& Pronczuk, J. Acute Pesticide Poisoning: A Proposed Classification Tool. Bulletin of The WHO 86 (3), 2008, pp. 205-209.

[24] Adhitya. Indian's Endosulfan Disaster: A Review of The Health Impacts and Status of Remediation. Kerala: Thanal, 2009, p. 3.

[25] Facing Hazards at Work-Agricultural Workers and Pesticides Exposure in Kuttanand, Kerala. Policy Brief SANDEE, 2007, p. 2.

[26] International Code of Conduct on The Distribution and Use of Pesticide. FAO, 2002, pp. 1-33.
[27] Decoding The International Code of Conduct on Pesticide Management. Croplife. DOI: https://croplife.org

[28] Stop Pesticide Poisoning! A Time Travel Through International Pesticide Policies. PAN Germany, 2016, pp. 6-20.

[29] The International Code of Conduct on Pesticide Management. FAO \& WHO, 2014.

[30] $10^{\text {th }}$ Joint Meeting on Pesticide Management. New Delhi: FAO\&WHO, 2013, p. 6.

[31] Quality Control of Pesticide in India. National Institute of Plant Health Management, Quarterly, Vol. 8, Issue, 1, 2018, p. 8. DOI: https://niphm.gov.in

[32] Ramavarman. Low Percentage of Pesticides Foaund in Kerala Vegetable Markets. Times of India, 2016.2 DOI: https://timesofindia.indiatimes.com

[33] 93,6\% Kerala Veggies Are Pesticide Free. Mathrubhumi, $2018 . \quad$ DOI: https://english.mathrubhumi.com

[34] Sudhakarna. Kerala To Set Up New Laboratories to Detect Pesticides in Vegetables. The Times of India, $2017 . \quad$ DOI: https://timesofindia.indiatimes.com 